\title{
Antecedents of positive self-disclosure online: an empirical study of US college students' Facebook usage
}

This article was published in the following Dove Press journal:

Psychology Research and Behavior Management

25 May 2017

Number of times this article has been viewed

\section{Hongliang Chen}

Department of Communication, Texas A\&M University, College

Station, TX, USA
Correspondence: Hongliang Chen Department of Communication, 4234 Texas A\&M University, College Station, TX 77843-4234, USA

$\mathrm{Tel}+\mathrm{I} 8606348677$

Fax +l 9798455500

Email hongliang.chen@tamu.edu
Abstract: This study investigates the factors predicting positive self-disclosure on social networking sites (SNSs). There is a formidable body of empirical research relating to online self-disclosure, but very few studies have assessed the antecedents of positive self-disclosure. To address this literature gap, the current study tests the effects of self-esteem, life satisfaction, social anxiety, privacy concerns, public self-consciousness (SC), and perceived collectivism on positive self-disclosure on SNSs. Data were collected online via Qualtrics in April 2013. Respondents were undergraduate students from the University of Connecticut. Using ordinary least squares regression, the current study found that self-esteem and perceived collectivism increased positive self-disclosure, life satisfaction, and privacy concerns decreased positive self-disclosure, and the effects of social anxiety and public SC were not significant.

Keywords: positive self-disclosure, self-esteem, life satisfaction, social anxiety, privacy concerns, public self-consciousness, perceived collectivism

\section{Introduction}

The emergence of social networking sites (SNSs) has transformed the means of interpersonal communication dramatically. Computer-mediated communication (CMC) eliminates people's social presence cues that decrease apprehension about communication. ${ }^{1}$ On SNSs, people can manage their self-presentations in a favorable way. ${ }^{2-5}$ SNS users selectively disclose thoughts, opinions, and feelings online. ${ }^{6,7}$ The eatures of SNSs, such as their settings of online or offline, the types of relationship, and the visibility of personal pages allow users to block unwanted viewers. ${ }^{7,8}$

Facebook is recognized as the most visited SNS. By the end of the second quarter of 2016, the number of active Facebook users was 1.7 billion. ${ }^{9}$ College students are the most active Facebook users. Previous studies found that college students spend 28 minutes per day on checking Facebook updates, which has become part of their daily routine. ${ }^{10}$ The benefits of Facebook include increased social capital, social well-being, and life satisfaction. ${ }^{3,4,10,11}$ Facebook users are concerned about impression management and tend to reveal positive aspects of their life. ${ }^{12}$ In previous SNS studies, the antecedents of positive self-disclosure online have not been examined systematically. To address this literature gap, the current study investigates the factors that may predict positive self-disclosure on SNSs, using data collected from the US Facebook users. 


\section{Literature review Self-esteem}

Self-esteem is a term used in psychology that refers to a person's emotional evaluation of his or her own worth. ${ }^{13}$ People's self-evaluation is based upon social norms and personal experiences. Self-esteem influences individual strategies in dealing with challenging situations and affects the way people communicate with others. ${ }^{14}$

Self-esteem is an influential predictor of self-disclosure by SNS users. Previous studies found that users with high self-esteem tend to be satisfied with life and post more photos and words about their daily life. ${ }^{15}$ On SNSs, people with high self-esteem who aspire to maintain a positive self-image are concerned about negative comments from online contacts. ${ }^{16}$ In contrast, those with low self-esteem tend to be socially anxious, shy, and introverted. ${ }^{17}$ Such individuals with low self-esteem are likely to perceive greater loneliness and lesser satisfaction in their relationship with others. ${ }^{18,19}$ The current study hypothesizes that high self-esteem leads to increased positive self-disclosure online.

H1: Self-esteem positively predicts positive selfdisclosure on SNSs.

\section{Life satisfaction}

Life satisfaction refers to people's general perceptions of their life quality. ${ }^{20}$ Researchers defined life satisfaction as people's positive feelings about their life according to their life expectation. ${ }^{21}$ In communication studies, life satisfaction is framed as subjective well-being or subjective personal statement. ${ }^{22}$ Life satisfaction is partly determined by standards of living. Income level, education, and social status can influence an individual's life satisfaction, ${ }^{23-25}$ as do existing social ties. ${ }^{26}$ Acceptance by friends, frequent interpersonal interactions, and active participation in social activities lead to happy feelings. People with high life satisfaction tend to receive greater social support than those with low self-satisfaction. ${ }^{22}$

Previous studies found that people who actively use Facebook feel happier and greater connectedness. ${ }^{10}$ In a personal crisis, an active Facebook user receives greater social support from families and friends. College students consider Facebook a major source of social interactions. Compared with the average population, college students spend more time on social activities, and friendships built in college last longer. ${ }^{27}$ College users who have more friends tend to be satisfied with life. ${ }^{10}$ Positive postings on Facebook can gain the attention of online contacts, which, in turn, strengthens social ties. In the current study, life satisfaction is expected to predict positive self-disclosure.
H2: Life satisfaction positively predicts positive selfdisclosure on SNSs.

\section{Social anxiety}

Social anxiety refers to an individual's worries about how one appears to others. People with high social anxiety are afraid of face-to-face social interactions. ${ }^{28}$ They spend less time with friends and are less likely to establish new relationships. ${ }^{29}$

Two hypotheses address the effect of social anxiety on self-disclosure on an SNS. The first hypothesis - social compensation theory - proposes that CMC is a powerful social interaction tool for people with deficient communication skills in face-to-face interactions. ${ }^{30,31}$ In CMC, people have more time to manage their self-presentation. Because of the lack of presence cues, CMC allows users to engage in communication with lesser stress. The controllability of CMC helps people to lower their apprehension with regard to communication. People with high social anxiety were found to be more comfortable and confident in CMC. ${ }^{32,33}$ However, this hypothesis has been challenged recently. Researchers found that although people with high social anxiety perceived Facebook as an appealing avenue for social interactions, their negative postings elicited undesirable comments from others. ${ }^{34}$ Negative responses from others were found to intensify apprehension about communication. The second hypothesis proposes that people with low social anxiety tend to be extroverts online and benefit more through online interactions. People with low social anxiety often perform better on expanding social networks through the Internet. ${ }^{35}$ In contrast, previous studies found that individuals with a higher level of social anxiety tended to self-disclose less during conversations as compared with non-anxious individuals. ${ }^{36}$ Extending this rationale into the context of Facebook, social anxiety may influence the valence of self-disclosure. Based on the so-called "rich get richer" assumption, the current study expects that low social anxiety would lead to more positive self-disclosure on Facebook.

H3: Social anxiety negatively predicts positive selfdisclosure on SNSs.

\section{Public self-consciousness}

Public self-consciousness (SC) is defined as "the attention to the self as a social object". ${ }^{37}$ Public SC affects the styles of interpersonal interaction. ${ }^{38,39}$ Individuals with high public SC are concerned about others' impressions about themselves, and this results in increased social anxiety and self-monitoring. Public SC was found to be associated with make-up choice, fashion opinion, and interest in clothing. ${ }^{40}$ 
Discrepancy between self-image and ideally defined image leads to increased social anxiety. ${ }^{40}$ People with high public $\mathrm{SC}$ tend to manage their self-presentation carefully and present positive aspects of their life to the public. ${ }^{41}$ Previous research found that individuals with high public SC post more photos and comments on SNSs..$^{5}$ The current study expects that public SC positively predicts positive self-disclosure.

H4: Public SC positively predicts positive self-disclosure on SNSs.

\section{Privacy concerns}

The Internet not only provides convenience for people but also provides opportunities for criminals. Within a few seconds, malicious agencies can collect a huge amount of private information from Internet users. ${ }^{42,43}$ Marketers can design soliciting information according to online postings of Internet users. The privacy invasion online can result in financial loss and relational conflicts with online contacts. ${ }^{44-46}$ Nowadays, Internet users have become increasingly concerned about the security of personal data online. ${ }^{47}$ Consistent with prior studies, the current study operationally defines privacy concerns as people's worries about potential privacy invasions online. ${ }^{48,49}$ For Facebook users, frequent postings of luxury purchases and travels may draw the attention of criminals and may aid criminals to design scam information accordingly. People with high privacy concerns are likely to be aware of the risks of show-off posts on SNSs. The current study expects that Facebook users with high privacy concerns tend to be cautious in risky positive self-disclosure.

H5: Privacy concerns negatively predict positive selfdisclosure on SNSs.

\section{Perceived collectivism}

People with different cultural backgrounds and life experiences tend to possess different perceptions of self, others, and the relationship between self and others. Differences in such perceptions influence people's social behaviors. ${ }^{50}$ In an individualist culture, people are autonomous and independent from other in-group members. Their behaviors are based on individual values rather than group norms. ${ }^{51}$ In a collectivist culture, people tend to rely on one another, give priority to collective norms, and behave unanimously. ${ }^{52}$ Previous research found that Internet users in individualist cultures tend to engage more in intentional self-disclosure online because they are less concerned about others' comments. ${ }^{53-55}$ In contrast, people with higher perceived collectivism tend to consider the feelings of other Facebook contacts and manage their self-presentations carefully. The current study expects that people with higher perceived collectivism are more likely to disclose positive aspects of their life.

H6: Perceived collectivism positively predicts positive self-disclosure on SNSs.

\section{Methods \\ Sample sources}

This survey study was approved by the Institutional Review Board of the University of Connecticut in March 2013. The survey was conducted on Qualtrics, which is an online survey platform, in April 2013. Participants were undergraduates from the University of Connecticut $(\mathrm{N}=368)$. Subjects read the informed consent first and then decided whether to continue the survey or not. All participants signed the informed consent. Because the focus of the current study is Facebook usage, subjects who were not Facebook users were excluded, resulting in a final sample size of 292. Consistent with prior studies, the missing values of continuous variables were replaced with a grand mean. ${ }^{56}$

\section{Measures}

The current study treated gender, race, and Internet efficacy as control variables. Most respondents identified themselves as White (77.74\%), followed by Asian (9.93\%), Arabic (7.19\%), African American (4.45\%), and Native American $(0.68 \%)$. In terms of gender, $38.14 \%$ of respondents were male. The current study used a 7-point scale to measure Internet efficacy. The result indicated that the majority of respondents perceived themselves to be proficient Internet users. Cronbach's $\alpha$ was used to assess the reliability of scale measurements. A previous study suggested that values greater than 0.70 are acceptable.$^{57}$ Descriptive statistics are presented further (Table 1).

\section{Self-esteem}

Adapted from a prior study, ${ }^{13}$ self-esteem was measured by asking respondents how they perceived themselves. Participants rated questions on a 7-point scale from 1 (strongly disagree) to 7 (strongly agree). The measurement was reliable (Cronbach's $a=0.85$ ). Respondents of the current study reported high self-esteem $(M=5.20, \mathrm{SD}=0.99)$.

\section{Life satisfaction}

Consistent with a prior study, life satisfaction was measured by five items to assess respondents' perceptions about their life. ${ }^{10}$ Responses ranged from 1 (strongly disagree) to 7 (strongly agree) $(M=4.79, \mathrm{SD}=1.13)$. The scaled measurement was reliable (Cronbach's $\alpha=0.85$ ). 
Table I Descriptive statistics of variables

\begin{tabular}{|c|c|c|c|c|c|}
\hline Variable & Mean & SD & Minimum & Maximum & Reliability ( $\alpha$ ) \\
\hline \multicolumn{6}{|l|}{ Exogenous variables } \\
\hline Male $^{\mathrm{a}}$ & $38.14 \%$ & & & & \\
\hline White $^{a}$ & $77.74 \%$ & & & & \\
\hline African American ${ }^{\mathrm{a}}$ & $4.45 \%$ & & & & \\
\hline Asian $^{\mathrm{a}}$ & $9.93 \%$ & & & & \\
\hline Native American ${ }^{\mathrm{a}}$ & $0.68 \%$ & & & & \\
\hline Arabic $^{\mathrm{a}}$ & $7.19 \%$ & & & & \\
\hline Internet efficacy & 5.18 & 1.02 & 1.57 & 7 & 0.84 \\
\hline \multicolumn{6}{|l|}{ Endogenous variables } \\
\hline Self-esteem & 5.20 & 0.99 & 2.29 & 7 & 0.85 \\
\hline Life satisfaction & 4.79 & 1.13 & 1.4 & 7 & 0.85 \\
\hline Social anxiety & 4.32 & 1.03 & I & 6.83 & 0.72 \\
\hline Public self-consciousness & 5.07 & 0.92 & 1.71 & 7 & 0.80 \\
\hline Privacy concerns & 4.04 & 1.18 & 1 & 6.9 & 0.90 \\
\hline Perceived collectivism & 5.09 & 0.89 & 2.33 & 7 & 0.75 \\
\hline Positive self-disclosure & 5.55 & 1.29 & I & 7 & 0.85 \\
\hline
\end{tabular}

Note: aPercentage of dichotomous variables.

\section{Social anxiety}

Social anxiety was measured by a scale with six items to assess people's anxiety about life, which is consistent with prior research. ${ }^{28}$ Responses ranged from 1 (strongly disagree) to 7 (strongly agree). The measurement was reliable (Cronbach's $a=0.72$ ). Respondents reported moderate levels of social anxiety $(M=4.32, \mathrm{SD}=1.03)$.

\section{Public SC}

Public SC was measured by a seven-item scale developed by a previous study.$^{38}$ Responses ranged from 1 (strongly disagree) to 7 (strongly agree) on people's concerns about others' impression about them. The measurement was reliable (Cronbach's $\alpha=0.80$ ). The result indicated that respondents were concerned about how they are viewed by others $(M=5.07, \mathrm{SD}=0.92)$.

\section{Privacy concerns}

Privacy concerns were measured using a 10-item scale, which is consistent with that reported in a previous study. ${ }^{58}$ Responses ranged from 1 (strongly disagree) to 7 (strongly agree). The scale measurement was reliable (Cronbach's $a=0.90$ ). Respondents reported moderate levels of privacy concerns $(M=4.04, \mathrm{SD}=1.18)$.

\section{Perceived collectivism}

Perceived collectivism was measured by a six-item scale developed in previous research. ${ }^{27}$ Responses ranged from 1 (strongly disagree) to 7 (strongly agree) $(M=5.09, \mathrm{SD}=0.89)$. The measurement was reliable (Cronbach's $a=0.75$ ).

\section{Positive self-disclosure}

Positive self-disclosure was measured with three items, which were adapted with a prior study. ${ }^{59}$ Responses ranged from 1 (strongly disagree) to 7 (strongly agree). In the current study, the scale measurement was reliable (Cronbach's $a=0.85$ ). Most respondents identified their self-disclosure on Facebook as positive $(M=5.55, \mathrm{SD}=1.29)$.

\section{Results}

Using STATA 13.0, the current study used ordinary least squares regression to test the hypothetical model, which is a method widely used to estimate the linear relationship between variables. ${ }^{60}$ The current study first tested the effects of control variables on the dependent variable (Model 1 in Table 2). Then, holding constants for control variables, the effects of the six antecedents on positive self-disclosure were examined (Model 2 in Table 2). The overall model fit was satisfactory $\left(R^{2}=0.32, p<0.001\right)$.

$\mathrm{H} 1$ posits that self-esteem positively predicts positive self-disclosure online. The effect was found to be positive and significant $(\beta=0.36, p<0.001)$. Thus, $\mathrm{H} 1$ was supported. $\mathrm{H} 2$ holds that individuals who are satisfied with their life are more likely to engage in positive self-disclosure online. Contrary to $\mathrm{H} 2$, the effect of life satisfaction was found to be negative $(\beta=-0.14, p<0.05)$. Thus, $\mathrm{H} 2$ was rejected. $\mathrm{H} 3$ proposes that social anxiety negatively predicts positive self-disclosure. Such an effect was found to be insignificant. Therefore, $\mathrm{H} 3$ was rejected. $\mathrm{H} 4$ holds that privacy concern is negatively associated with positive self-disclosure and was supported in the current study $(\beta=-0.10, p<0.05)$. H5 posits 
Table 2 Standardized ordinary least squares regression predicting positive self-disclosure $(\mathrm{N}=292)$

\begin{tabular}{lll}
\hline Variable & Model I & Model 2 \\
\hline Exogenous control variables & & \\
Gender & $0.17^{* *}$ & $0.14^{* *}$ \\
Black & 0.03 & 0.03 \\
Asian & $-0.20^{* * *}$ & $-0.17^{* *}$ \\
Latino & -0.08 & -0.04 \\
Native & -0.01 & -0.04 \\
Arabic & 0.02 & 0.01 \\
Internet efficacy & $0.28^{* * *}$ & 0.03 \\
Endogenous independent variables & & \\
Self-esteem & & $0.36^{* * *}$ \\
Life satisfaction & & $-0.14^{*}$ \\
Social anxiety & & -0.08 \\
Privacy concerns & & $-0.10^{*}$ \\
Public self-consciousness & & 0.05 \\
Perceived collectivism & & $0.19^{* *}$ \\
$R^{2}$ & $0.19^{* * *}$ & $0.32^{* * *}$ \\
\hline
\end{tabular}

Note: $*_{p}<0.05 ; * * p<0.01 ; * * * p<0.001$.

that public SC positively predicts positive self-disclosure online. Such an effect was found to be insignificant. Thus, H5 was rejected. $\mathrm{H} 6$ assumes that perceived collectivism leads to increased positive self-disclosure, and was supported in this study $(\beta=0.19, p<0.01)$.

\section{Discussion}

The current study provides a preliminary test of the factors predicting positive self-disclosure on SNSs. A positive effect of self-esteem on positive self-disclosure was documented. This finding suggested that individuals with high self-esteem tend to be concerned about others' impressions about them. To enhance their positive self-image, they are likely to disclose positive aspects of their life on SNSs. Facebook users can edit their postings strategically to draw the attention of contacts and receive more positive feedback. Prior studies found that, in face-to-face interactions, individuals use feedback from others to evaluate their self-presentation. ${ }^{61,62}$ Extending this rationale to SNSs, users use positive feedback from others to maintain their self-esteem.

Consistent with prior studies, ${ }^{48,63,64}$ college-going respondents of the current study reported high privacy concerns. College students actively use the Internet for information search, school assignments, and entertainment. SNSs satisfy the needs of college students to establish new contacts and maintain existing relationships. ${ }^{10}$ Their frequent use of the Internet increases their chances of being victims of privacy invasion, which, in turn, increase privacy concerns. Additionally, cyber security education on campus and high Internet efficacy help college students to develop better understanding of privacy risks online. College students are likely to monitor unauthorized access into personal SNS accounts and install antivirus software to protect their data online.

Another finding of this study is that people's privacy concerns negatively predict positive self-disclosure on SNSs. Prior research found that hackers and solicitors become increasingly reliant on SNSs to contact target victims. ${ }^{65}$ They distribute malware through SNSs and design phishing postings to seduce SNS users. ${ }^{66}$ For instance, if she or he posts a photo of a newly purchased auto vehicle, hackers are likely to design phishing information pertaining to auto insurance. Show-off posts on SNSs increase the risk of privacy invasion. The finding of the current study suggested that people with high privacy concerns tend to understand the mechanism of cyber-attacks. To reduce privacy risks, they tend to use neutral words in their postings to avoid the attention of cyber criminals.

Another interesting finding is that perceived collectivism positively predicts positive self-disclosure. This finding suggests that Facebook users who tend to give a group priority over individual needs tend to reveal the positive side of their life. Such positive self-disclosure can bring enhanced happiness to other group members and strengthen existing social ties. ${ }^{3}$ In a public space like Facebook, collectivists are likely to please others. In a personal crisis, people with higher perceived collectivism tend to exchange ideas with friends using private communication channels, such as telephone and instant messaging, but not SNSs.

Contrary to existing research, ${ }^{3,10}$ the current study found that life satisfaction is negatively associated with positive self-disclosure online. People with high life satisfaction tend to perceive that their current living standards have met their life expectation ${ }^{67}$ Prior studies found that people with high life satisfaction tend to be rich, healthy, and well-educated. ${ }^{23}$ The finding of the current study suggested that people with high life satisfaction tend to pay less attention to others' negative comments online. On SNSs, they are willing to disclose negative aspects of their life honestly.

In the current study, the effects of social anxiety and public SC were found to be insignificant. This finding provides support for the coexistence of the two hypotheses of social anxiety. For some people with high social anxiety, they can build enhanced self-image on Facebook. The anonymity feature of SNSs makes such individuals confident in self-presentation online. For other people with high social anxiety, the assumption of "the rich get richer" persists. They post more negative words online. 
The effect of public SC on positive self-disclosure can be more complicated. People with higher perceived public SC may simply avoid online interactions if they are concerned about others' critiques. For people who rarely engage in online interactions, it is difficult to judge the valence of self-disclosure on SNSs.

\section{Limitations and implications for future research}

Three major limitations should be noted. First, the use of cross-sectional data cannot test causal relationships. Future studies with panel data can provide a more rigorous test on the antecedents of positive self-disclosure. Second, selfreport measures can be biased in measuring self-esteem, life satisfaction, social anxiety, and positive self-disclosure. Respondents may overestimate self-esteem, life satisfaction, and the valence of self-disclosure, but may underestimate social anxiety. Future research should use other research methods to quantify these concepts. For instance, to assess the valence of self-disclosure, content analysis of one's Facebook account can be more accurate than a self-reported survey. Third, the backgrounds of online contacts may impact SNS users' patterns of self-disclosure. For instance, child users behave differently when their SNS accounts are connected to that of their parents. ${ }^{68}$ Future research should study individual strategies of self-disclosure in different online contexts.

\section{Disclosure}

The author reports no conflicts of interest in this work.

\section{References}

1. Hunt D, Atkin D, Krishnan A. The influence of computer-mediated communication apprehension on motives for Facebook use. J Broadcast Electron Media. 2012;56(2):187-202.

2. Chou HT, Edge N. "They are happier and having better lives than I am": the impact of using Facebook on perceptions of others' lives. Cyberpsychol Behav Soc Netw. 2012;15(2):117-121.

3. Kim J, Lee JE. The Facebook paths to happiness: effects of the number of Facebook friends and self-presentation on subjective well-being. Cyberpsychol Behav Soc Netw. 2011;14(6):359-364.

4. Mehdizadeh S. Self-presentation 2.0: narcissism and self-esteem on Facebook. Cyberpsychol Behav Soc Netw. 2010;13(4):357-364.

5. Shim M, Lee MJ, Park SH. Photograph use on social network sites among South Korean college students: the role of public and private self-consciousness. Cyberpsychol Behav. 2008;11(4):489-493.

6. Qian H, Scott CR. Anonymity and self-disclosure on weblogs. J Comput Mediat Commun. 2007;12(4):1428-1451.

7. Zhao S, Grasmuck S, Martin J. Identity construction on Facebook: digital empowerment in anchored relationships. Comput Human Behav. 2008;24(5):1816-1836.

8. Li-Barber KT. Self-disclosure and student satisfaction with Facebook. Comput Human Behav. 2012;28(2):624-630.
9. STATISTA. Number of monthly active Facebook users worldwide as of 2nd quarter 2016 (in millions). Secondary number of monthly active Facebook users worldwide as of 2nd quarter 2016 (in millions). Available from: https://www.statista.com/statistics/264810/number-of-monthlyactive-facebook-users-worldwide/. Accessed May 1, 2017.

10. Ellison NB, Steinfield C, Lampe C. The benefits of Facebook "Friends": social capital and college students' use of online social network sites. J Comput Mediat Commun. 2007;12(4):1143-1168.

11. Gonzales AL, Hancock JT. Mirror, mirror on my Facebook wall: effects of exposure to Facebook on self-esteem. Cyberpsychol Behav Soc Netw. 2011;14(1-2):79-83.

12. Rosenberg J, Egbert N. Online impression management: personality traits and concerns for secondary goals as predictors of self-presentation tactics on Facebook. J Comput Mediat Commun. 2011;17(1):1-18.

13. Rosenberg M. Society and the Adolescent Self-Image. Princeton, NJ: Princeton University Press; 1965.

14. Barker V. Older adolescents' motivations for social network site use: the influence of gender, group identity, and collective self-esteem. Cyberpsychol Behav. 2009;12(2):209-213.

15. Valkenburg PM, Peter J, Schouten AP. Friend networking sites and their relationship to adolescents' well-being and social self-esteem. Cyberpsychol Behav. 2006;9(5):584-590.

16. Wang JL, Jackson LA, Zhang DJ, Su ZQ. The relationships among the Big Five Personality factors, self-esteem, narcissism, and sensationseeking to Chinese University students' uses of social networking sites (SNSs). Comput Human Behav. 2012;28(6):2313-2319.

17. Donnellan MB, Trzesniewski KH, Robins RW, Moffitt TE, Caspi A. Low self-esteem is related to aggression, antisocial behavior, and delinquency. Psychol Sci. 2005;16(4):328-335.

18. Leary MR, MacDonald G. Individual differences in self-esteem: a review and theoretical integration. In: Leary MR, Tangney JP, editors. Handbook of Self and Identity. New York, NY: The Guilford Press; 2003:401-418.

19. Wood JV, Hogle AL, McClellan JC. Self-esteem, effects on relationships. In: Reis HT, Sprecher S, editors. Encyclopedia of Human Relationships. Thousand Oaks, CA: Sage; 2009:1422-1425.

20. Arslan C, Hamarta E, Uslu M. The relationship between conflict communication, self-esteem and life satisfaction in university students. Educ Res Rev. 2010;5(1):31-34.

21. Diener E. Subjective well-being. The science of happiness and a proposal for a national index. Am Psychol. 2000;55(1):34-43.

22. Valenzuela S, Park N, Kee KF. Is there social capital in a social network site?: Facebook use and college students' life satisfaction, trust, and participation. J Comput Mediat Commun. 2009;14(4):875-901.

23. Boyce CJ, Brown GD, Moore SC. Money and happiness rank of income, not income, affects life satisfaction. Psychol Sci. 2010;21(4): 471-475.

24. Frijters P, Haisken-DeNew JP, Shields MA. Money does matter! Evidence from increasing real income and life satisfaction in East Germany following reunification. Am Econ Rev. 2004;94(3):730-740.

25. Rohe WM, Stegman MA. The effects of homeownership: on the selfesteem, perceived control and life satisfaction of low-income people. J Am Plann Assoc. 1994;60(2):173-184.

26. Kahneman D, Krueger AB. Developments in the measurement of subjective well-being. J Econ Perspect. 2006;20(1):3-24.

27. Triandis HC, Gelfand MJ. Converging measurement of horizontal and vertical individualism and collectivism. J Pers Soc Psychol. 1998;74(1):118-128.

28. La Greca AM, Lopez N. Social anxiety among adolescents: linkages with peer relations and friendships. J Abnorm Child Psychol. 1998;26(2):83-94.

29. Gilbert P. The relationship of shame, social anxiety and depression: the role of the evaluation of social rank. Clin Psychol Psychother. 2000;7(3):174-189.

30. Walther JB. Computer-mediated communication: impersonal, interpersonal, and hyperpersonal interaction. Commun Res. 1996;23(1):3-43. 
31. Walther JB, Anderson JF, Park DW. Interpersonal effects in computermediated interaction: a meta-analysis of social and antisocial communication. Commun Res. 1994;21(4):460-487.

32. McKenna KYA, Green AS, Gleason MEJ. Relationship formation on the Internet: what's the big attraction? J Soc Issues. 2002;58(1): 9-31.

33. Stritzke WG, Nguyen A, Durkin K. Shyness and computer-mediated communication: a self-presentational theory perspective. Media Psychol. 2004;6(1):1-22.

34. Forest AL, Wood JV. When social networking is not working: individuals with low self-esteem recognize but do not reap the benefits of self-disclosure on Facebook. Psychol Sci. 2012;23(3):295-302.

35. Kraut R, Kiesler S, Boneva B, Cummings J, Helgeson V, Crawford A. Internet paradox revisited. J Soc Issues. 2002;58(1):49-74.

36. Pilkonis PA. The behavioral consequences of shyness. J Pers. 1977;45(4):596-611.

37. Reno RR, Kenny DA. Effects of self-consciousness and social anxiety on self-disclosure among unacquainted individuals: an application of the social relations model. J Pers. 1992;60(1):79-94.

38. Fenigstein A, Scheier MF, Buss AH. Public and private selfconsciousness: assessment and theory. J Consult Clin Psychol. 1975;43(4):522-527.

39. Tobey EL, Tunnell G. Predicting our impressions on others effects of public self-consciousness and acting, a self-monitoring subscale. Pers Soc Psychol Bull. 1981;7(4):661-669.

40. Miller FG, Davis LL, Rowold KL. Public self-consciousness, social anxiety, and attitudes toward the use of clothing. Fam Consum Sci. 1982;10(4):363-368.

41. Fenigstein A. Self-consciousness and the overperception of self as a target. J Pers Soc Psychol. 1984;47(4):860-870.

42. Chen H, Beaudoin CE, Hong T. Protecting oneself online: the effects of negative privacy experiences on privacy protective behaviors. J Mass Commun Q. 2016;93(2):409-429.

43. Chen H, Beaudoin CE, Hong T. Securing online privacy: an empirical test on internet scam victimization, online privacy concerns, and privacy protection behaviors. Comput Human Behav. 2017;70:291-302.

44. Pratt TC, Holtfreter K, Reisig MD. Routine online activity and Internet fraud targeting: extending the generality of routine activity theory. $J$ Res Crime Delinq. 2010;47(3):267-296.

45. Reisig MD, Pratt TC, Holtfreter K. Perceived risk of Internet theft victimization: examining the effects of social vulnerability and financial impulsivity. Crim Justice Behav. 2009;36(4):369-384.

46. Sánchez Abril P, Levin A, Del Riego A. Blurred boundaries: social media privacy and the twenty first century employee. Am Bus Law J. 2012;49(1):63-124.

47. Li H, Sarathy R, Xu H. Understanding situational online information disclosure as a privacy calculus. J Comput Inf Syst. 2010;51(1): $62-71$.

48. Youn S. Teenagers' perceptions of online privacy and coping behaviors: a risk-benefit appraisal approach. J Broadcast Electron Media. 2005;49(1):86-110.
49. Youn S. Determinants of online privacy concern and its influence on privacy protection behaviors among young adolescents. J Consum Aff. 2009;43(3):389-418.

50. Markus HR, Kitayama S. Culture and the self: implications for cognition, emotion, and motivation. Psychol Rev. 1991;98(2):224-253.

51. Triandis HC. Individualism-collectivism and personality. J Pers. 2001;69(6):907-924.

52. Mills J, Clark MS. Review of Personality and Social Psychology. Beverly Hills, CA: Sage; 1982.

53. Kim H, Papacharissi Z. Cross-cultural differences in online selfpresentation: a content analysis of personal Korean and US home pages. Asian J Commun. 2003;13(1):100-119.

54. Ma R. Computer-mediated conversations as a new dimension of intercultural communication between East Asian and North American college students. In: Herring SC, editor. Computer-Mediated Communication: Linguistic, Social, and Cross-cultural Perspectives. Amsterdam, NY: John Benjamins; 1996:173-185.

55. Yum YO, Hara K. Computer-mediated relationship development: a crosscultural comparison. J Comput Mediat Commun. 2005;11(1):133-152.

56. Tabachnick BG, Fidell LS. Using Multivariate Statistics. 5th ed. Boston, MA: Pearson; 2007.

57. Tavakol M, Dennick R. Making sense of Cronbach's alpha. Int J Med Educ. 2011;2:53-55.

58. Buchanan T, Paine C, Joinson AN, Reips UD. Development of measures of online privacy concern and protection for use on the Internet. $\mathrm{JAm}$ Soc Inf Sci Technol. 2007;58(2):157-165.

59. Leung L. Loneliness, self-disclosure, and ICQ ("I Seek You”) use. Cyberpsychol Behav. 2002;5(3):241-251.

60. Dhillon PS, Fosert DP, Kakade SM, Ungar LH. A risk comparison of ordinary least squares vs ridge regression. J Mach Learn Res. 2013;14(1):1505-1511.

61. Duval S, Duval VH, Neely R. Self-focus, felt responsibility, and helping behavior. J Pers Soc Psychol. 1979;37(10):1769-1778.

62. Storms MD. Videotape and the attribution process: reversing actors' and observers' points of view. J Pers Soc Psychol. 1973;27(2):165-175.

63. Chen H, Beaudoin CE, Hong T. Teen online information disclosure: empirical testing of a protection motivation and social capital model. J Assoc Inf Sci Technol. 2016;67(12):2871-2881.

64. Cho H, Lee JS, Chung S. Optimistic bias about online privacy risks: testing the moderating effects of perceived controllability and prior experience. Comput Human Behav. 2010;26(5):987-995.

65. Debatin B, Lovejoy JP, Horn AK, Hughes BN. Facebook and online privacy: attitudes, behaviors, and unintended consequences. J Comput Mediat Commun. 2009;15(1):83-108.

66. Weir GRS, Toolan F, Smeed D. The threats of social networking: old wine in new bottles? Inf Security Tech Rep. 2011;16(2):38-43.

67. Peterson C, Park N, Seligman MEP. Orientations to happiness and life satisfaction: the full life versus the empty life. J Happiness Stud. 2005;6(1):25-41.

68. O'Keeffe GS, Clarke-Pearson K. The impact of social media on children, adolescents, and families. Pediatrics. 2011;127(4):800-804.
Psychology Research and Behavior Management

\section{Publish your work in this journal}

Psychology Research and Behavior Management is an international, peerreviewed, open access journal focusing on the science of psychology and its application in behavior management to develop improved outcomes in the clinical, educational, sports and business arenas. Specific topics covered in the journal include: Neuroscience, memory and decision making; Behavior modification and management; Clinical applications; Business and sports performance management; Social and developmental studies; Animal studies. The manuscript management system is completely online and includes a very quick and fair peer-review system, which is all easy to use. Visit http://www. dovepress.com/testimonials.php to read real quotes from published authors. 